OPEN ACCESS

Edited by:

Valeria Costantino,

University of Naples Federico II, Italy

Reviewed by:

Hyun Lee,

University of Illinois at Chicago,

United States

Jun-Seok Lee,

Korea Institute of Science and

Technology (KIST), South Korea

${ }^{*}$ Correspondence:

Andriy Luzhetskyy

a.luzhetskyy@mx.uni-saarland.de

Specialty section:

This article was submitted to

Medicinal and Pharmaceutical

Chemistry,

a section of the journa

Frontiers in Chemistry

Received: 04 September 2019 Accepted: 12 December 2019

Published: 10 January 2020

Citation:

Rodríguez Estévez M, Gummerlich N,

Myronovskyi M, Zapp J and

Luzhetskyy A (2020) Benzanthric Acid,

a Novel Metabolite From

Streptomyces albus Del14 Expressing

the Nybomycin Gene Cluster.

Front. Chem. 7:896.

doi: 10.3389/fchem.2019.00896

\section{Benzanthric Acid, a Novel Metabolite From Streptomyces albus Del14 Expressing the Nybomycin Gene Cluster}

\author{
Marta Rodríguez Estévez ${ }^{1}$, Nils Gummerlich ${ }^{1}$, Maksym Myronovskyi ${ }^{1}$, Josef Zapp ${ }^{2}$ and \\ Andriy Luzhetskyy ${ }^{1,3 *}$
}

${ }^{1}$ Pharmaceutical Biotechnology, University of Saarland, Saarbrücken, Germany, ${ }^{2}$ Department of Pharmacy, Institute of Pharmaceutical Biology, University of Saarland, Saarbrücken, Germany, ${ }^{3}$ Helmholtz Institute for Pharmaceutical Research Saarland, Saarbrücken, Germany

Streptomycetes constitute a diverse bacterial group able to produce a wide variety of secondary metabolites with potential applications in the pharmacy industry. However, the genes responsible for the biosynthesis of these compounds are very frequently inactive or expressed at very low levels under standard laboratory cultivation conditions. Therefore, the activation or upregulation of secondary metabolite biosynthesis genes is a crucial step for the discovery of new bioactive natural products. We have recently reported the discovery of the biosynthetic genes for the antibiotic nybomycin (nyb genes) in Streptomyces albus subsp. chlorinus. The nyb genes were expressed in the heterologous host Streptomyces albus Del14, which produces not only nybomycin, but also a novel compound. In this study, we describe the isolation, purification, and structure elucidation of the new substance named benzanthric acid.

Keywords: benzanthric acid, biosynthetic gene cluster, heterologous expression, nybomycin, secondary metabolite, Streptomyces

\section{INTRODUCTION}

Numerous species of the actinomycetal genus Streptomyces harbor metabolic pathways that produce secondary metabolites with a broad spectrum of bioactivities, which in many cases represent potential drug leads for the development of pharmaceuticals (Paulus et al., 2017; Protasov et al., 2017). The biosynthetic genes for these metabolites are generally arranged in clusters whose expression is often very low under laboratory cultivation conditions. Therefore, diverse strategies have been developed in order to induce the biosynthesis of natural products in Streptomyces strains (McKenzie et al., 2010; Olano et al., 2014; English et al., 2017). A widely used approach consists in the heterologous expression of a specific gene cluster in an optimized host strain where some of the native secondary metabolite genes have been removed (Myronovskyi et al., 2018; Bu et al., 2019). The simplified metabolic background promotes the channeling of biosynthetic precursors toward the production of the heterologous metabolites and facilitates their identification.

The marine strain Streptomyces albus subsp. chlorinus NRRL B-24108 is responsible for the production of bioactive metabolites such as the herbicide albucidin and the antibiotic nybomycin (Hahn et al., 2009; Rodriguez Estevez et al., 2018). We have recently discovered the biosynthetic genes for nybomycin (nyb genes) in S. albus subsp. chlorinus through a heterologous expression approach using the chassis strain Streptomyces albus Del14 as a host (Rodriguez Estevez et al., 2018). 
Besides nybomycin, we detected a new metabolite in the extract of $S$. albus $4 \mathrm{~N} 24$ expressing the $n y b$ genes. In this study, we report the isolation, purification and structure elucidation of the novel compound, benzanthric acid, from the culture of Streptomyces albus $4 \mathrm{~N} 24$.

\section{MATERIALS AND METHODS}

\section{General Experimental Procedures}

Streptomyces and Escherichia coli strains used in this work are listed in Supplementary Table 1. LB medium was used for cultivation of $E$. coli strains according to standard protocols (Green and Sambrook, 2012). Streptomyces strains were cultivated in standard media (Kieser et al., 2000): soy flour mannitol agar (MS agar) and liquid tryptic soy broth (TSB; Sigma-Aldrich, St. Louis, MO, USA). Additionally, liquid DNPM medium (40 g/L dextrin, $7.5 \mathrm{~g} / \mathrm{L}$ soytone, $5 \mathrm{~g} / \mathrm{L}$ baking yeast, and $21 \mathrm{~g} / \mathrm{L}$ MOPS, $\mathrm{pH}$ 6.8) was used for secondary metabolite expression. The following antibiotics were supplemented when required at concentrations of $50 \mu \mathrm{g} / \mu \mathrm{l}$ (solid medium) or 25 $\mu \mathrm{g} / \mu \mathrm{l}$ (liquid medium): kanamycin, apramycin, and nalidixic acid (Carl Roth, Germany; Sigma-Aldrich, USA).

\section{Isolation and Manipulation of DNA}

Bacterial artificial chromosome (BAC) 4 N24 was isolated from a library comprising the genome of Streptomyces albus subsp. chlorinus (Intact Genomics, St. Louis, MO, USA). DNA manipulations and cloning procedures including $E$. coli transformation and intergeneric conjugation between $E$. coli/Streptomyces were performed following standard protocols (Kieser et al., 2000; Green and Sambrook, 2012; Rebets et al., 2017). Plasmid DNA was purified with the BACMAX ${ }^{\mathrm{TM}}$ DNA purification kit (Lucigen, Middleton, WI, USA). Restriction endonucleases were used for plasmid diagnostic test (New England Biolabs, Ipswich, MA, USA).

\section{Metabolite Extraction and Analysis}

Streptomyces albus $4 \mathrm{~N} 24$ as well as the control strains Streptomyces albus De14 and Streptomyces albus subsp. chlorinus were cultivated in $15 \mathrm{~mL}$ TSB medium for $24 \mathrm{~h}$ at $28^{\circ} \mathrm{C}$. Main cultures containing $50 \mathrm{~mL}$ of DNPM were inoculated with $1 \mathrm{~mL}$ of pre-culture. After 7 days of cultivation at $28^{\circ} \mathrm{C}$, the secreted metabolites were extracted with ethyl acetate and butanol, followed by solvent evaporation. The dry extracts were solved in $1 \mathrm{~mL}$ methanol and $1 \mu \mathrm{L}$ of the solved sample was separated using a Dionex Ultimate 3000 UPLC (Thermo Fisher Scientific, Waltham, MA, USA), and a 10-cm ACQUITY UPLC ${ }^{\circledR} \mathrm{BEH}$ C18 column, $1.7 \mu \mathrm{m}$ (Waters, Milford, MA, USA). The mobile phase was comprised of two solvents: formic acid solved in acetonitrile $(0.1 \%)$ and formic acid solved in water $(0.1 \%)$. Solvent concentrations varied in a linear gradient from 5 to $95 \%$ in $18 \mathrm{~min}$ at a flow rate of $0.6 \mathrm{~mL} / \mathrm{min}$. The UPLC system was coupled either to amaZon speed mass spectrometer or maXis high-resolution LC-QTOF system (Bruker, USA), allowing the mass spectrometry analysis of the extracts. The software Bruker Compass Data Analysis version 4.1 (Bruker, Billerica, MA, USA) was used for data analysis. Monoisotopic mass was searched in the natural product database DNP (Dictionary of Natural Products; Buckingham, 1993).

\section{Benzanthric Acid Isolation and Nuclear Magnetic Resonance (NMR) Spectroscopy}

A flask containing $30 \mathrm{~mL}$ TSB medium was inoculated with $S$. albus $4 \mathrm{~N} 24$ and incubated at $28^{\circ} \mathrm{C}$ for $24 \mathrm{~h}$. The production culture consisted of $10 \mathrm{~L}$ divided into 100 flasks, each containing $100 \mathrm{~mL}$ DNPM medium and inoculated with $1 \mathrm{~mL}$ of preculture. After 7 days of cultivation at $28^{\circ} \mathrm{C}$, metabolite extraction was performed as described above. The crude extract was fractionated by size-exclusion chromatography on an $\mathrm{LH}$ 20 Sephadex column (Sigma-Aldrich, USA) using methanol as the mobile phase. Resulting fractions were analyzed by LC-MS and those containing benzanthric acid were further separated by preparative HPLC (Waters 2545 Binary Gradient module, Waters, Milford, MA, USA) using a Nucleodur ${ }^{\circledR}$ C18 HTec column $(5 \mu \mathrm{m}, 250 \times 21 \mathrm{~mm}$, Macherey-Nagel, Düren, Germany) with a linear gradient of $0.1 \%$ formic acid solution in methanol against $0.1 \%$ formic acid solution in water, yielding $5 \mathrm{mg}$ of benzanthric acid. UV spectra were recorded with a PAD detector (Photodiode Array Detector, Waters 2998, Waters, Milford, MA, USA). All reported NMR spectra were recorded at $298 \mathrm{~K}$ on a Bruker Avance 500 with a $5 \mathrm{~mm}$ BBO probe (Bruker, BioSpin $\mathrm{GmbH}$, Rheinstetten, Germany) using DMSO- $\mathrm{d}_{6}$ (deuterated dimethyl sulfoxide) as solvent. The solvent peak was used as an internal standard and set to $\delta_{\mathrm{H}} 2.49$ for the ${ }^{1} \mathrm{H}-\mathrm{NMR}$ and $\delta_{\mathrm{C}} 39.50$ for the ${ }^{13} \mathrm{C}-\mathrm{NMR}$, respectively. For the structural elucidation the following spectra were recorded with standard pulse programs: ${ }^{1} \mathrm{H}-\mathrm{NMR},{ }^{13} \mathrm{C}$ NMR, ${ }^{1} \mathrm{H}_{-}{ }^{1} \mathrm{H}$-correlated spectroscopy (COZY), heteronuclear single quantum spectroscopy (HSQC), heteronuclear multiple bond correlation (HMBC), and rotating frame Overhauser enhancement spectroscopy (ROESY, spin-lock: $300 \mathrm{~ms}$ ).

\section{Feeding Experiment With Anthranilic Acid (Phenyl- ${ }^{13} \mathrm{C}_{6}$ )}

Two flasks containing $25 \mathrm{~mL}$ of DNPM medium were inoculated with $S$. albus $4 \mathrm{~N} 24$ as described above (Section Metabolite Extraction and Analysis). One of the cultures was supplemented with $5 \mathrm{mg} / \mathrm{mL}$ of anthranilic acid (phenyl- ${ }^{13} \mathrm{C}_{6}$ ) (Cambridge Isotope Laboratories, Andover, MA, USA) at intervals of $12 \mathrm{~h}$ for 4 days, while the second one was used as a control. After further $24 \mathrm{~h}$ cultivation, the metabolites were extracted from the supernatant as described in Section Metabolite Extraction and Analysis.

\section{Antimicrobial Susceptibility Test}

Susceptibility tests were performed by the disk diffusion method described in Bauer et al. (1966). Ten $\mathrm{mL}$ of $\mathrm{LB}$ soft agar (10 g/l tryptone, $10 \mathrm{~g} / \mathrm{l} \mathrm{NaCl}, 5 \mathrm{~g} / \mathrm{l}$ yeast extract, $7 \mathrm{~g} / \mathrm{l}$ agar) were inoculated with the strains Escherichia coli GB2005, Bacillus subtilis ATCC 6633 or Pseudomonas putida KT2440 and poured on LB agar plates. Four paper disks 
(Macherey and Nagel, Düren, Germany) were coated with $100,50,10$, and $0.5 \mu \mathrm{g}$ of benzanthric acid solved in DMSO, respectively, and placed onto the solidified soft agar. DMSO was used as a negative control and the antibiotics ampicillin, chloramphenicol, and nalidixic acid $(50 \mathrm{mg} / \mathrm{mL}$, respectively) as positive controls. The plates were incubated at $28^{\circ} \mathrm{C}$ overnight.

\section{Herbicidal Pre-emergence Test}

Seeds of Agrostis stolonifera (Juliwa HESA, Heidelberg, Germany) were placed into the wells of a 96-well microtiter plate (Sarstedt, Nümbrecht, Germany). A solution containing $2.2 \mathrm{~g} / \mathrm{l}$ Murashige \& Skoog plant salts (Serva, Heidelberg, Germany) and $1.6 \mathrm{~g} / \mathrm{l}$ Gamborg's B5 plant medium (Serva, Heidelberg, Germany) was added to the wells. Decreasing concentrations of benzanthric acid solved in DMSO were added $(2 \mathrm{mM}, 1 \mathrm{mM}, 0.5 \mathrm{mM}$, $0.25 \mathrm{mM}, 125 \mu \mathrm{M}$, and $62.5 \mu \mathrm{M})$. Identical volumes of DMSO without benzanthric acid were used as a toxicity test of the organic solvent. The solution containing the plant medium was used as a negative control. The plate was closed and incubated at room temperature under constant light (Osram Fluora lamp) in a humidity chamber. After 3 days of incubation, the plate lid was removed and a container with tap water was placed inside the chamber for increasing the air humidity. The plate was incubated up to 6 days. Three technical replicates were performed.

\section{Genome Mining and Bioinformatics Analysis}

The online tool antiSMASH (https://antismash. secondarymetabolites.org/\#!/start) was used for the identification of secondary metabolite biosynthetic gene clusters in the genome of $S$. albus subsp. chlorinus (Weber et al., 2015). Gene cluster analysis was performed with the help of the software Geneious 11.0.3 (Kearse et al., 2012).

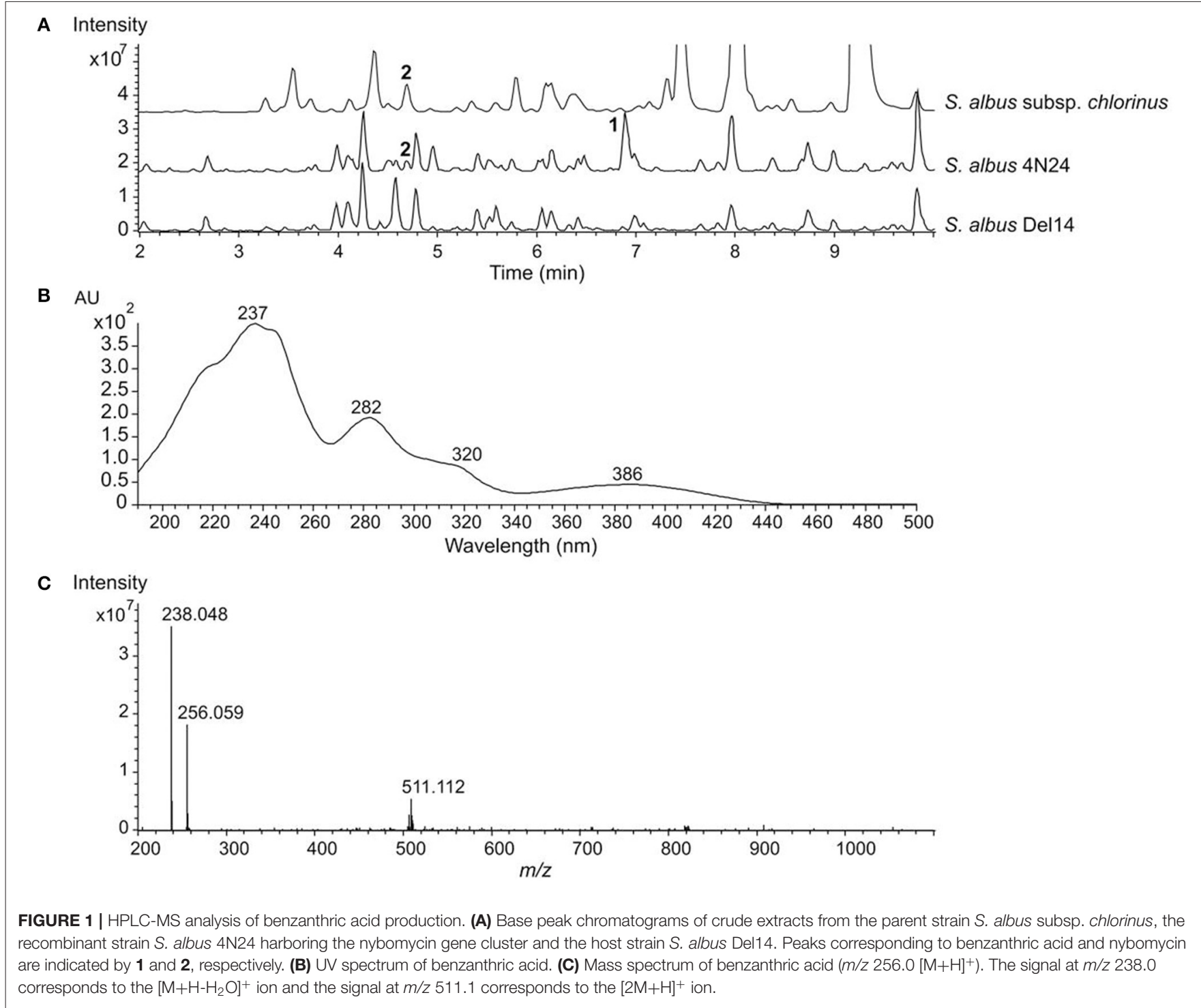




\section{RESULTS}

We have previously reported the identification of the nybomycin gene cluster from S. albus subsp. chlorinus NRRL B-24108 through heterologous expression of BAC $4 \mathrm{~N} 24$ harboring the $n y b$ genes in the host S. albus Del14 (Rodriguez Estevez et al., 2018). In addition to nybomycin, the HPLC-MS analysis of an extract from the recombinant strain $S$. albus $4 \mathrm{~N} 24$ expressing the $n y b$ genes revealed the presence of a peak at $\mathrm{t}_{\mathrm{R}}=6.9 \mathrm{~min}$ and $\mathrm{m} / z 256.059[\mathrm{M}+\mathrm{H}]^{+}$ (Figure 1), exhibiting UV absorption signals at $\lambda_{\max } 237$, 282, 320, and $386 \mathrm{~nm}$ (Figure 1B). Unlike nybomycin, which is produced by both $S$. albus $4 \mathrm{~N} 24$ and the parent strain S. albus subsp. chlorinus, the peak at $\mathrm{m} / \mathrm{z} 256.059$ was solely detected in the extract of S. albus 4N24 (Figure 1). The search of the monoisotopic mass 255.051 in a natural product database yielded no coincidences, which suggested a putatively new compound and encouraged us to purify it for structure elucidation.

After seven days of cultivation of the strain S. albus $4 \mathrm{~N} 24$ in $10 \mathrm{~L}$ of DNPM liquid medium, the broth was centrifuged and the metabolites were extracted from the supernatant. The extract was fractionated by size-exclusion chromatography through a Sephadex column followed by preparative high performance liquid chromatography (HPLC) to yield $5 \mathrm{mg}$ of the novel metabolite benzanthric acid (Figure 2A). The molecular formula of benzanthric acid was determined as $\mathrm{C}_{14} \mathrm{H}_{9} \mathrm{NO}_{4}$ by high-resolution electrospray ionization mass spectrometry (HRESMS) and NMR $(\mathrm{m} / \mathrm{z}$ 256.05949, $-3.688 \mathrm{ppm})$. The analysis of the ${ }^{13} \mathrm{C}-\mathrm{NMR}(125 \mathrm{MHz}$, DMSO- $\mathrm{d}_{6}$ ) revealed the presence of fourteen carbons. Two carbons were assigned as carbonyl groups $\left(\delta_{C} 168.67 \mathrm{C}-1\right.$, 160.22 C-9). The twelve remaining carbons were assigned as olefinic carbons $\left(\delta_{\mathrm{C}} 135.28 \mathrm{C}-6,133.40 \mathrm{C}-5 \mathrm{a}, 129.95[2 \mathrm{x}] \mathrm{C} 7\right.$ \& C8, 122.58 C-5, 122.34 C-4a, 121.52 C-8a, 118.57 C-10, 113.29 C-2, $108.84 \mathrm{C}-4)$ including one oxygenated carbon $\left(\delta_{C} 140.59 \mathrm{C}-9 \mathrm{a}\right)$ and one aminated carbon $\left(\delta_{C} 147.81 \mathrm{C}-\right.$ 3; Supplementary Figures 1-3). The ${ }^{1} \mathrm{H}-\mathrm{NMR}$ (500 MHz, DMSO- $\left.\mathrm{d}_{6}\right)$ showed six aromatic signals: $\delta_{\mathrm{H}} 8.24(1 \mathrm{H}, \mathrm{dd}$; $\left.\mathrm{J}_{1,2}=7.9,1.1 \mathrm{~Hz} ; \mathrm{H}-8\right), \delta_{\mathrm{H}} 8.16(1 \mathrm{H}, \mathrm{d}, \mathrm{J}=8.1 \mathrm{~Hz}, \mathrm{H}-5), \delta_{\mathrm{H}}$ $7.96\left(1 \mathrm{H}, \mathrm{dt}, \mathrm{J}_{1,2}=7.7,1.1 \mathrm{~Hz}, \mathrm{H}-6\right), \delta_{\mathrm{H}} 7.70\left(1 \mathrm{H}, \mathrm{dt}, \mathrm{J}_{1,2}=\right.$ 7.6, $0.6 \mathrm{~Hz}, \mathrm{H}-7), \delta_{\mathrm{H}} 7.64(1 \mathrm{H}, \mathrm{s}, \mathrm{H}-10)$, and $\delta_{\mathrm{H}} 7.57(1 \mathrm{H}$, s, H-4; Supplementary Figures 1, 4-6). The ${ }^{1} \mathrm{H}-{ }^{1} \mathrm{H}-\mathrm{COZY}$ spectrum showed correlations between $\mathrm{H}-5$ and $\mathrm{H}-6, \mathrm{H}-6$ and H-7, H-7, and H-8 (Supplementary Figures 7, 8). The phase sensitive HSQC spectrum revealed eight quaternary carbons (C-1, C-2, C-3, C-4a, C-5a, C-8a, C-9, and C9a; Supplementary Figures 9, 10). Through correlation in the heteronuclear multiple bond correlation (HMBC) experiment connections between the spin systems were

TABLE 1 | NMR chemical shifts and 2D correlations of benzanthric acid.

\begin{tabular}{|c|c|c|c|c|}
\hline Position & $\begin{array}{c}\delta^{13} \mathrm{C}[\mathrm{ppm}]^{\mathrm{a}} \\
\text { type }\end{array}$ & $\begin{array}{c}\delta^{1} \mathrm{H}[\mathrm{ppm}]^{\mathrm{b}} \\
(\mathrm{J} \text { in } \mathrm{Hz})\end{array}$ & coZY & HMBC $^{c}$ \\
\hline 1 & $168.67 \mathrm{C}$ & - & - & - \\
\hline 2 & $113.29 \mathrm{C}$ & - & - & - \\
\hline 3 & $147.81 \mathrm{C}$ & - & - & - \\
\hline 4 & $108.84 \mathrm{CH}$ & $7.57 \mathrm{~s}$ & - & $\begin{array}{c}\text { C-1, C-2, C-3, } \\
\text { C-5a, C-9a, C-10 }\end{array}$ \\
\hline $4 a$ & $122.34 \mathrm{C}$ & - & - & - \\
\hline $5 a$ & $133.40 \mathrm{C}$ & - & - & - \\
\hline 5 & $122.58 \mathrm{CH}$ & $8.16 \mathrm{~d}(8.1)$ & 6 & $\begin{array}{c}\text { C-4a, C-5a, C-6, } \\
\text { C-8, C-8a, C-9 }\end{array}$ \\
\hline 6 & $135.28 \mathrm{CH}$ & $\begin{array}{c}7.96 \mathrm{dt}(7.7 \\
1.1)\end{array}$ & $5 ; 7$ & C-5a, C-7, C-8 \\
\hline 7 & $129.95 \mathrm{CH}$ & $\begin{array}{c}7.70 \mathrm{dt}(7.6 \\
0.6)\end{array}$ & $6 ; 8$ & $\begin{array}{l}\text { C-5, C-5a, C-6, } \\
\text { C-8, C-8a, C-9 }\end{array}$ \\
\hline 8 & $129.95 \mathrm{CH}$ & $\begin{array}{c}8.24 \mathrm{dd}(7.9 \\
1.1)\end{array}$ & 7 & C-5a, C-6, C-9 \\
\hline $8 a$ & $121.52 \mathrm{C}$ & - & - & - \\
\hline 9 & $160.22 \mathrm{C}$ & - & - & - \\
\hline $9 a$ & $140.59 \mathrm{C}$ & - & - & - \\
\hline 10 & $118.57 \mathrm{CH}$ & $7.64 \mathrm{~s}$ & - & $\begin{array}{c}\text { C-1, C-2, C-4, } \\
\text { C-4a, C-5a, C-9a, } \\
\text { C-10 }\end{array}$ \\
\hline $\mathrm{COOH}^{d}$ & - & $7.00-9.50 \mathrm{~s} \mathrm{br}$ & - & - \\
\hline $\mathrm{NH}_{2}^{\mathrm{d}}$ & - & $7.00-9.50 \mathrm{~s} \mathrm{br}$ & - & - \\
\hline
\end{tabular}

${ }^{a} 125 \mathrm{MHz}$ for ${ }^{13} \mathrm{C}-\mathrm{NMR}$.

${ }^{b} 500 \mathrm{MHz}$ for ${ }^{1} \mathrm{H}-\mathrm{NMR}$.

${ }^{C} \mathrm{HMBC}$ correlations from protons to the indicated carbons.

${ }^{d}$ Exchangeable protons.

\section{A}<smiles>Nc1cc2c(cc1C(=O)O)oc(=O)c1ccccc12</smiles>

B<smiles>CC1=CC(=O)N2COC3=C2C(=O)C=C2C=C(CO)C1=C23</smiles>

C<smiles>Nc1ccccc1C(=O)O</smiles>

FIGURE 2 | Chemical structures of (A) benzanthric acid, (B) nybomycin and (C) anthranilic acid. 

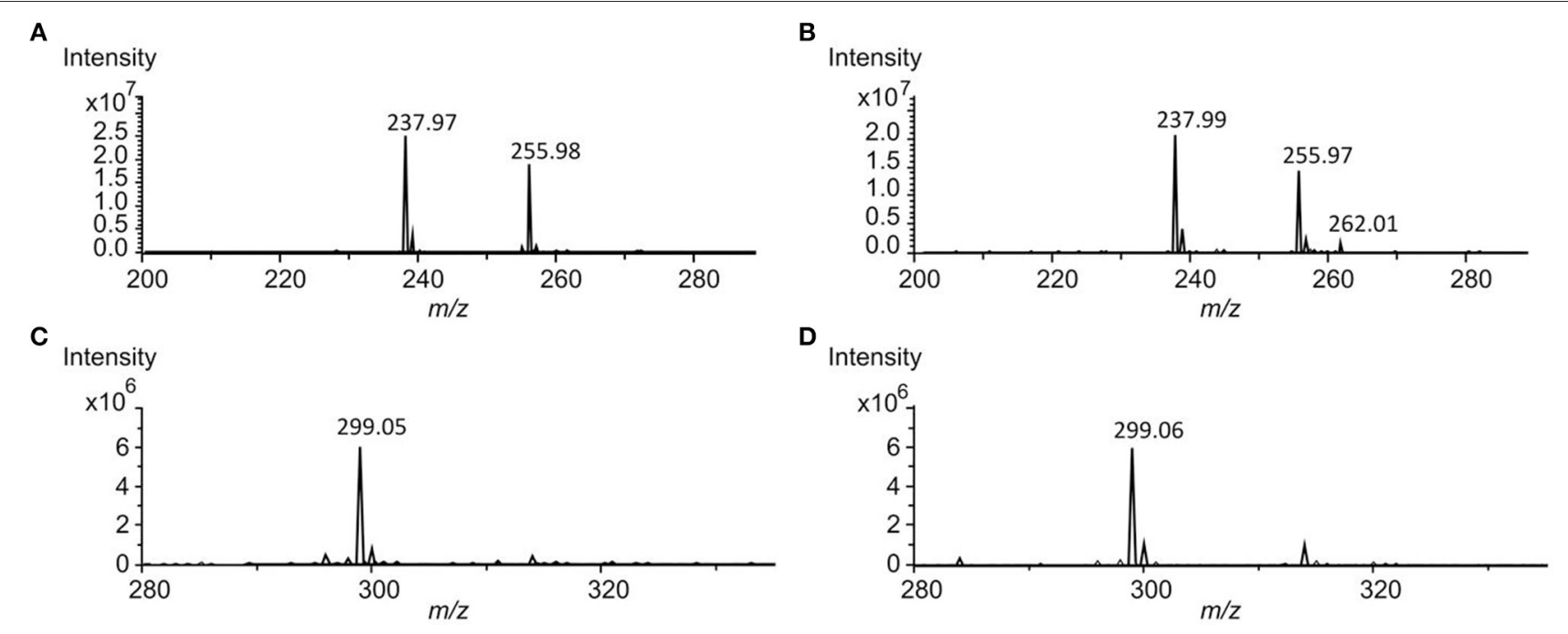

FIGURE 3 | Analysis of anthranilic acid (phenyl- ${ }^{13} \mathrm{C}_{6}$ ) incorporation. (A) Mass spectrum of benzanthric acid $\left(\mathrm{m} / \mathrm{z} 255.9[\mathrm{M}+\mathrm{H}]^{+}\right)$extracted from the culture of $\mathrm{S}$. albus 4N24. The signal at $\mathrm{m} / \mathrm{z} 237.9$ corresponds to the $\left[\mathrm{M}+\mathrm{H}-\mathrm{H}_{2} \mathrm{O}\right]^{+}$ion. (B) Mass spectrum of benzanthric acid extracted from the culture of S. albus 4N24 fed with anthranilic acid (phenyl- ${ }^{13} \mathrm{C}_{6}$ ). The signal at $\mathrm{m} / \mathrm{z} 262.0$ corresponds to the $[\mathrm{M}+\mathrm{H}]^{+}$ion after incorporation of the labeled anthranilic acid. (C) Mass spectrum of nybomycin $\left(\mathrm{m} / \mathrm{z} 299.0[\mathrm{M}+\mathrm{H}]^{+}\right)$extracted from the culture of $S$. albus 4N24. (D) Mass spectrum of nybomycin extracted from the culture of $S$. albus 4N24 fed with anthranilic acid (phenyl- ${ }^{13} \mathrm{C}_{6}$ ). No incorporation of anthranilic acid can be detected.

identified (Supplementary Figures 11, 12). The complete list including all correlations can be found in Table 1. Important correlations to establish connections between the spin systems were $\mathrm{H}-4$ to $\mathrm{C}-5 \mathrm{a}, \mathrm{H} 5$ to $\mathrm{C}-4 \mathrm{a}$ as well as $\mathrm{H}-10$ to $\mathrm{C}-4 \mathrm{a}$ and $\mathrm{C}-4$. A ${ }^{15} \mathrm{~N}-\mathrm{HMBC}$ experiment revealed the correlation between $\mathrm{H}-4$ and the nitrogen of the primary aromatic amine (Supplementary Figure 13). The ROESY spectrum showed a correlation through space between $\mathrm{H}-4$ and H-5 (Supplementary Figure 14).

Benzanthric acid's structure has been determined as a benzoate part bound to an anthranilate moiety. This arrangement considerably differs from the core structure of nybomycin (Figures 2A,B), which is also produced by the strain $S$. albus $4 \mathrm{~N} 24$ harboring the $n y b$ genes. In order to test whether anthranilic acid functions as a precursor in the biosynthesis of benzanthric acid and nybomycin, a culture of S. albus $4 \mathrm{~N} 24$ was fed with anthranilic acid (phenyl- ${ }^{13} \mathrm{C}_{6}$ ) (Figure 2C). HPLCMS analysis of the resulting extract revealed the incorporation of the labeled anthranilate into the structure of benzanthric acid. The mass spectrum of benzanthric acid shows two signals: a signal at $m / z 256$ corresponding to the $[\mathrm{M}+\mathrm{H}]^{+}$ion of the compound and a signal at $\mathrm{m} / z 238$ corresponding to its derivative after water loss (Figure 3A). After feeding with labeled anthranilic acid an additional signal at $\mathrm{m} / z \quad 262$ is observed (Figure 3B), implying the incorporation of the $\operatorname{six}{ }^{13} \mathrm{C}$ atoms of the labeled anthranilate into benzanthric acid. No incorporation of anthranilic acid into the structure of nybomycin was detected (Figures 3C,D).

The antimicrobial activity of benzanthric acid against the Gram-negative bacteria Escherichia coli and Pseudomonas putida, as well as the Gram-positive bacterium Bacillus subtilis was assayed through disk diffusion test, revealing no growth inhibitory activity (Supplementary Figure 15A). The herbicidal activity of the new metabolite was tested against the monocot grass species Agrostis stolonifera. The purified benzanthric acid was added to the plant seeds and incubated in a minimal medium. Seed germination was observed after 3 days, indicating no inhibitory effect against the tested plant (Supplementary Figure 15B).

\section{DISCUSSION}

In this paper, we describe the isolation and chemical structure elucidation of the novel metabolite benzanthric acid, produced by $S$. albus $4 \mathrm{~N} 24$ containing the nybomycin biosynthetic gene cluster. The strain simultaneously produces nybomycin and benzanthric acid, suggesting that both compounds might share common biosynthetic steps. The structure of benzanthric acid (Figure 2A) suggests anthranilate and benzoate as possible biosynthetic precursors. The precursor role of anthranilic acid has been proved by feeding studies. Interestingly, no incorporation of anthranilic acid into nybomycin's structure could be detected, indicating substantial differences in the biosynthetic routes leading to nybomycin and benzanthric acid.

In living organisms, anthranilic acid is mainly synthesized either through the shikimate pathway or through the tryptophan degradation pathway (Haslam, 1974; Kurnasov et al., 2003). One of the nybomycin biosynthetic genes, $n y b F$, encodes a putative 3Deoxy-D-arabinoheptulosonate 7-phosphate (DAHP) synthase, which catalyzes the first reaction of the shikimate pathway. Since the DAHP synthase controls the amount of carbon entering the pathway, the expression of the $n y b F$ gene can lead to 
its upregulation and increased intracellular concentrations of benzanthric acid's precursor-anthranilic acid. Additionally, the product of the $n y b D$ gene shows homology at the protein level with anthranilate synthase and might be also responsible for the additional supply of anthranilic acid. In this case, anthranilic acid is most probably only a by-product of the enzyme's reaction, since it was shown not to be a precursor of nybomycin biosynthesis.

We propose that benzoic acid serves as the second direct precursor for benzanthric acid production. No genes which could lead to the biosynthesis of benzoic acid were identified within the DNA fragment containing the nybomycin cluster. Therefore, it is likely that benzoic acid is provided by the metabolism of the host strain S. albus Del14. The phenylalanine degradation pathway could be responsible for the supply of this precursor (Tabor and Tabor, 1970).

The attachment of benzoic acid to the anthranilate moiety is necessary for the formation of benzanthric acid. The enzyme catalyzing this biosynthetic step could not be identified within the nybomycin gene cluster. We propose that the required enzyme is encoded by the genome of the host strain $S$. albus Del14. This is further supported by the data revealing no production of benzanthric acid by the original nybomycin producer (Figure 1A).

The fact that the new compound, benzanthric acid, could be generated through the expression of the characterized nybomycin gene cluster in the well-studied heterologous host $S$. albus Del14 is intriguing. The isolated compound can be found neither in the extracts of the natural nybomycin producer nor in that of

\section{REFERENCES}

Bauer, A. W., Kirby, W. M., Sherris, J. C., and Turck, M. (1966). Antibiotic susceptibility testing by a standardized single disk method. Am. J. Clin. Pathol. 45, 493-496. doi: 10.1093/ajcp/45.4_ts.493

Bu, Q. T., Yu, P., Wang, J., Li, Z. Y., Chen, X., Mao, X.-M., et al. (2019). Rational construction of genome-reduced and high-efficient industrial Streptomyces chassis based on multiple comparative genomic approaches. Microb. Cell Fact. 18:16. doi: 10.1186/s12934-01 9-1055-7

Buckingham, J. (1993). Dictionary of Natural Products. London: CRC Press/Taylor and Francis Group.

English, A. L., Boufridi, A., Quinn, R. J., and Kurtboke, D. I. (2017). Evaluation of fermentation conditions triggering increased antibacterial activity from a near-shore marine intertidal environment-associated Streptomyces species. Synthe. Syst. Biotechnol. 2, 28-38. doi: 10.1016/j.synbio.2016. 09.005

Green, M. R., and Sambrook, J. (2012). Molecular Cloning: A Laboratory Manual. New York, NY: Cold Spring Harbor Laboratory Press.

Hahn, D. R., Graupner, P. R., Chapin, E., Gray, J., Heim, D., Gilbert, J. R. et al. (2009). Albucidin: a novel bleaching herbicide from Streptomyces albus subsp. chlorinus NRRL B-24108. J. Antibiot. 62, 191-194. doi: 10.1038/ja. 2009.11

Haslam, E. (1974). The Shikimate Pathway. London: Butterworth.

Kearse, M., Moir, R., Wilson, A., Stones-Havas, S., Cheung, M., Sturrock, S., et al. (2012). Geneious basic: an integrated and extendable desktop software platform for the organization and analysis of sequence data. Bioinformatics 28, 1647-1649. doi: 10.1093/bioinformatics/ bts199

Kieser, T. B. M. J., Buttner, M., J., Charter, K. F., and Hopwood, D. (2000). Practical Streptomyces Genetics. Norwich, UK: John Innes Foundation. the heterologous host S. albus Del14. Benzanthric acid is also not a degradation product of nybomycin. The most plausible explanation for the origin of the isolated compound is the interplay between the host's metabolism and the introduced biosynthetic pathway. The isolation of benzanthric acid raises the question of whether this is rather an exception or the integration of foreign metabolic pathways or their parts into the host's metabolism can be used as a tool for the generation of new natural products.

\section{DATA AVAILABILITY STATEMENT}

The datasets generated for this study can be found in the GenBank under accession number MH924838.

\section{AUTHOR CONTRIBUTIONS}

MR, MM, and AL designed the experiments. MR performed the experiments. NG and JZ performed and evaluated the NMR analysis. MR, NG, and MM wrote the manuscript. All the authors reviewed the manuscript.

\section{SUPPLEMENTARY MATERIAL}

The Supplementary Material for this article can be found online at: https://www.frontiersin.org/articles/10.3389/fchem. 2019.00896/full\#supplementary-material
Kurnasov, O., Jablonski, L., Polanuyer, B., Dorrestein, P., Begley, T., and Osterman, A. (2003). Aerobic tryptophan degradation pathway in bacteria: novel kynurenine formamidase. FEMS Microbiol. Lett. 227, 219-227. doi: 10.1016/S0378-1097(03)00684-0

McKenzie, N. L., Thaker, M., Koteva, K., Hughes, D. W., Wright, G., Nodwell, J. R., et al. (2010). Induction of antimicrobial activities in heterologous streptomycetes using alleles of the Streptomyces coelicolor gene absA1. J. Antibiot. 63, 177-182. doi: 10.1038/ja.2010.13

Myronovskyi, M., Rosenkranzer, B., Nadmid, S., Pujic, P., Normand, P., and Luzhetskyy, A. (2018). Generation of a cluster-free Streptomyces albus chassis strains for improved heterologous expression of secondary metabolite clusters. Metabol. Eng. 49, 316-324. doi: 10.1016/j.ymben.2018.09.004

Olano, C., Garcia, I., Gonzalez, A., Rodriguez, M., Rozas, D., Rubio, J., et al. (2014). Activation and identification of five clusters for secondary metabolites in Streptomyces albus J1074. Microb. Biotechnol. 7, 242-256. doi: 10.1111/1751-7915.12116

Paulus, C., Rebets, Y., Tokovenko, B., Nadmid, S., Terekhova, L. P., Myronovskyi, M., et al. (2017). New natural products identified by combined genomicsmetabolomics profiling of marine Streptomyces sp. MP131-18. Sci. Rep. 7:42382. doi: $10.1038 /$ srep 42382

Protasov, E. S., Axenov-Gribanov, D. V., Rebets, Y. V., Voytsekhovskaya, I., Shatilina, Z.M., et al. (2017). The diversity and antibiotic properties of actinobacteria associated with endemic deepwater amphipods of Lake Baikal. Antonie Van Leeuwenhoek 110, 1593-1611. doi: 10.1007/s10482-017-0910-y

Rebets, Y., Kormanec, J., Lutzhetskyy, A., Bernaerts, K., and Anne, J. (2017). "Cloning and expression of metagenomic DNA in Streptomyces lividans and subsequent fermentation for optimized production," in Metagenomics. Methods in Molecular Biology, eds W. Streit and R. Daniel (New York, NY: Humana Press).

Rodriguez Estevez, M., Myronovskyi, M., Gummerlich, N., Nadmid, S., and Luzhetskyy, A. (2018). Heterologous expression of the nybomycin 
gene cluster from the marine strain Streptomyces albus subsp. chlorinus NRRL B-24108. Mar. Drugs 16:E435. doi: 10.3390/md16 110435

Tabor, H., and Tabor, C. W. (1970). "Metabolism of amino acids and amines," in Methods in Enzymology, eds S. P. Colowick and N. O. Kaplan (New York, NY: Academic Press), 415-678.

Weber, T., Blin, K., Duddela, S., Krug, D., Kim, H., U., Bruccoleri, R., et al. (2015). antiSMASH 3.0-a comprehensive resource for the genome mining of biosynthetic gene clusters. Nucleic Acids Res. 43, W237-W243. doi: $10.1093 /$ nar/gkv437
Conflict of Interest: The authors declare that the research was conducted in the absence of any commercial or financial relationships that could be construed as a potential conflict of interest.

Copyright () 2020 Rodríguez Estévez, Gummerlich, Myronovskyi, Zapp and Luzhetskyy. This is an open-access article distributed under the terms of the Creative Commons Attribution License (CC BY). The use, distribution or reproduction in other forums is permitted, provided the original author(s) and the copyright owner(s) are credited and that the original publication in this journal is cited, in accordance with accepted academic practice. No use, distribution or reproduction is permitted which does not comply with these terms. 